\title{
Conducting K-12 Outreach to Evoke Early Interest in IT, Science, and Advanced Technology
}

\author{
Kristy Kallback-Rose* \\ Indiana University \\ 2709 E. Tenth Street \\ Bloomington, IN 47408 \\ 812-856-7122 \\ kallbac@iu.edu
}

\author{
Danko Antolovic \\ Indiana University \\ 2709 E. Tenth Street \\ Bloomington, IN 47408 \\ 812-855-3579 \\ dantolov@iu.edu
}

\author{
Robert Ping \\ Pervasive Technology Institute, \\ Indiana University \\ 2719 E. Tenth Street \\ Bloomington, IN 47408 \\ 812-345-1065 \\ robping@indiana.edu
}

\begin{abstract}
The Indiana University Pervasive Technology Institute has engaged for several years in K-12 Education, Outreach and Training (EOT) events related to technology in general and computing in particular. In each event we strive to positively influence children's perception of science and technology. We view K-12 EOT as a channel for technical professionals to engage young people in the pursuit of scientific and technical understanding. Our goal is for students to see these subjects as interesting, exciting, and worth further pursuit. By providing opportunities for pre-college students to engage in science, technology, engineering and mathematics (STEM) activities first hand, we hope to influence their choices of careers and field-ofstudy later in life.

In this paper we give an account of our experiences with providing EOT: we describe several of our workshops and events; we provide details regarding techniques that we found to be successful in working with both students and instructors; we discuss program costs and logistics; and we describe our plans for the future.
\end{abstract}

\section{Categories and Subject Descriptors}

K.3.2 [Computers and Education]: Computer and Information Science Education - computer science education, curriculum, information systems education.

\section{General Terms}

PREPRINT: THIS SPACE RESERVED FOR COPYRIGHT NOTICE
Economics, Human Factors

\section{Keywords}

K-12, education, outreach, training, EOT, STEM, children, workshops.

\section{INTRODUCTION}

There are many motivators for doing outreach with K-12 students. First and foremost, we consistently face two realities: there is a lack of people trained in science, technology, engineering, and mathematics (STEM) disciplines in general and scientific computing in particular to fill the need for skilled academics and professionals in the US research community. Second, there are many people in the US who would be capable of filling such positions, but lack the necessary training. This is widely recognized as a "pipeline problem," i.e. at all levels, there is a shortage of degreed professionals in STEM areas because not enough students are entering academic programs in these fields [1]. A recent report by the President's Council of Advisors on Science and Technology (PCAST) included the statement "PCAST found that economic forecasts point to a need for producing, over the next decade, approximately 1 million more college graduates in STEM fields than expected under current assumptions" [14].

This shortage of trained researchers and professionals affects the eXtreme Science and Engineering Discovery Environment (XSEDE) as it does many areas of research and infrastructure delivery supported by the NSF. A routine observation within the XSEDE organization and many of the institutions participating in XSEDE is that it is hard to find enough skilled people to fill jobs. Many US institutions are hiring extremely talented people who are nationals of countries other than the US. Domestically, there are many Americans who have neither good jobs nor the education that would enable them to have a good job. These two facts cannot persist perpetually into the future. First, at some level it becomes globally unfair for the US to continually retain some of the best talent from other countries that come here to

*Presenting author 
study. Second, as institutions funded at least in part by taxes on Americans, we have a responsibility to be attentive to the needs of US society. Goals to improve education and the STEM workforce in the US are goals deeply engrained in guidance from the National Science Foundation (NSF). The NSF Cyberinfrastructure Framework for $21^{\text {st }}$ Century Science and Engineering (CIF21) vision statement talks about accelerating research and education. One of the two fundamental criteria in reviewing grant proposals submitted to the NSF is "broader impacts," where education and outreach are core aspects of this criterion.

However, XSEDE has made a strategic decision not to invest in outreach at the K-12 level. At a certain level this makes sense, and there are good arguments in favor of the outreach directions chosen by XSEDE. It is reasonable for XSEDE as an organization and for the staff funded by XSEDE to focus on outreach to undergraduates, graduate students, and disciplines that currently make little use of advanced cyberinfrastructure. Indeed, this strategy is very consistent with recommendations in the PCAST report cited earlier. But XSEDE includes many large centers, most of which have extremely talented staff who would be willing and able to operate effective K-12 outreach programs. Many of those large centers have a history of offering K-12 programs. If we are to affect the pipeline of STEM-trained workers, and create a better educated workforce, some attention to K-12 outreach seems an important part of the collective mission of the US research community in general and cyberinfrastructure community in particular. It would be particularly helpful if, in addition to the education and outreach efforts by large centers we could add practical programs that could be effectively delivered by the many more smaller advanced computing centers and technology research groups in the US.

The purpose of this paper is to describe some of the K-12 outreach efforts that have been completed at Indiana University by the Pervasive Technology Institute, describe some of the outcomes we have had so far, discuss the amount of staff effort it has taken to put on these activities, and publicize the availability of materials that others in the community can reuse (and as needed adapt) so that other institutions can offer their own K-12 activities with minimal cost in terms of materials and effort.

\section{CHARGE FOR IU K-12 OUTREACH AND ANTICIPATED OUTCOMES}

Indiana University has as a key element of its overall mission a particular responsibility for public education. Indiana University President Michael McRobbie in his inaugural speech noted that, "We are [also] a public university supported by and with a responsibility to the citizens of Indiana. They expect us to provide a great education to their sons and daughters; they expect us to do the best research and scholarship; and they expect us to be engaged in the life of the State."[11] More specifically, there is an outreach goal included in "Empowering People - Indiana University's Strategic Plan for Information Technology" [5]. Action 50 of that plan is: "K-12 Outreach - IU should use its distinct capabilities in education and technology to reach out to K-12 teachers, administrators, and students in ways that further an effective primary through post-secondary (P-20) approach to improve Hoosier education."

Within the IT organizations at Indiana University, the Pervasive Technology Institute [9] has been assigned a leadership role for K-12 outreach, particularly with developing K-12 programs relevant to computing and informatics. PTI is an innovative collaboration of the IU School of Informatics and Computing, Office of the Vice President for Information Technology, University Information Technology Services, Maurer School of Law, and College of Arts and Sciences. PTI thus has many resources on which to draw in developing outreach programs and an organizational charge so to do.

One of the primary goals of each outreach activity is to foster interest in, and awareness of, science and technology. We also seek to make these subjects approachable and wherever possible tangible; i.e., hands-on. Our expectations for education, outreach, and training (EOT) include self-discovery, by the students, that science and technology activities are interesting and worth further pursuit. In a successful workshop we will witness students having "aha!" discovery moments, building self-confidence in solving problems, learning to work in a group setting, and feeling a sense of accomplishment at the end of an activity; i.e., something was built or something was discovered. Put more succinctly, we seek to provide a high-quality learning experience that children will enjoy. That is only one step in the many that are required for a young person to successfully decide to pursue an education and career in a STEM field - but it is one of the key early steps.

\section{TYPES OF OUTREACH}

PTI engages in a number of different types of outreach activities. A complete list of PTI outreach events appears in Table 1, and a full report summarizing all PTI education and outreach events is available online [12]. In this paper we focus on K-12 outreach - in which we engage in science and technology endeavors directly with young people and with educators (teach the teachers).

With students, we have a limited window of opportunity with each group, so we have to be realistic about how much impact we can have on any individual child's decision to later enter a field related to science or technology. Still, direct engagement affects dozens of children per year, and over the course of years hundreds. Furthermore, our delivery of outreach activities directly provides us both the material and the experience to enable us to work effectively and credibly with educators.

\subsection{Outreach Directly Engaging K-12 Students}

PTI's focus in K-12 outreach has been in the repeated offering and refinement of three different outreach programs. They are, in order of increasing duration of the program: fiber optics and laser light; Lego Mindstorms ${ }^{\circledR}$ robotics programming; and "No guts, no glory" - a set of exercises that teaches networking and computer principles. Descriptions of these workshops follow.

\subsubsection{Fiber Optics and Laser Light}

The learning goal of the fiber optics and laser light activity is to provide a basic understanding of the way light travels along fiber optic cables and how light can be used to transmit data. Fiber optics is a commonly used term in commercials and so it is easy for the students to make a connection between a technology relevant to their world and the science learned from experiments that they perform themselves. The learning is accomplished through hands on experimentation with the transmission of colored light beams via streams of water. This activity has been done successfully in a classroom setting and in a walk-up, booth-style demonstration. 
In the classroom session, we begin with a very brief discussion of the phenomenon of light to get the students thinking about the different types of light, and the remainder of the session consists of hands-on exercises. First, we give the students a transparent, half-moon-shaped piece of plastic and a laser pointer. The students are asked to experiment with what happens when the laser light encounters the half-moon and then guided to achieve different combinations of refraction and reflection. Next, a yardlong polycarbonate tube is used to demonstrate how total internal reflection allows the light to stay within the tube, even if the tube is bent. In the third experiment, students are divided into groups of three or four and allowed to see for themselves how light will follow the path of a curved stream of water. We accomplish this by filling a 2-litre bottle, which is punctured midway down, with water and letting a stream flow into a catch tray beneath. When the students shine the laser beam through the back of the bottle and out through the puncture, they see that the beam does not continue on a straight path but instead follows the curved path of the water (see Figure 1).

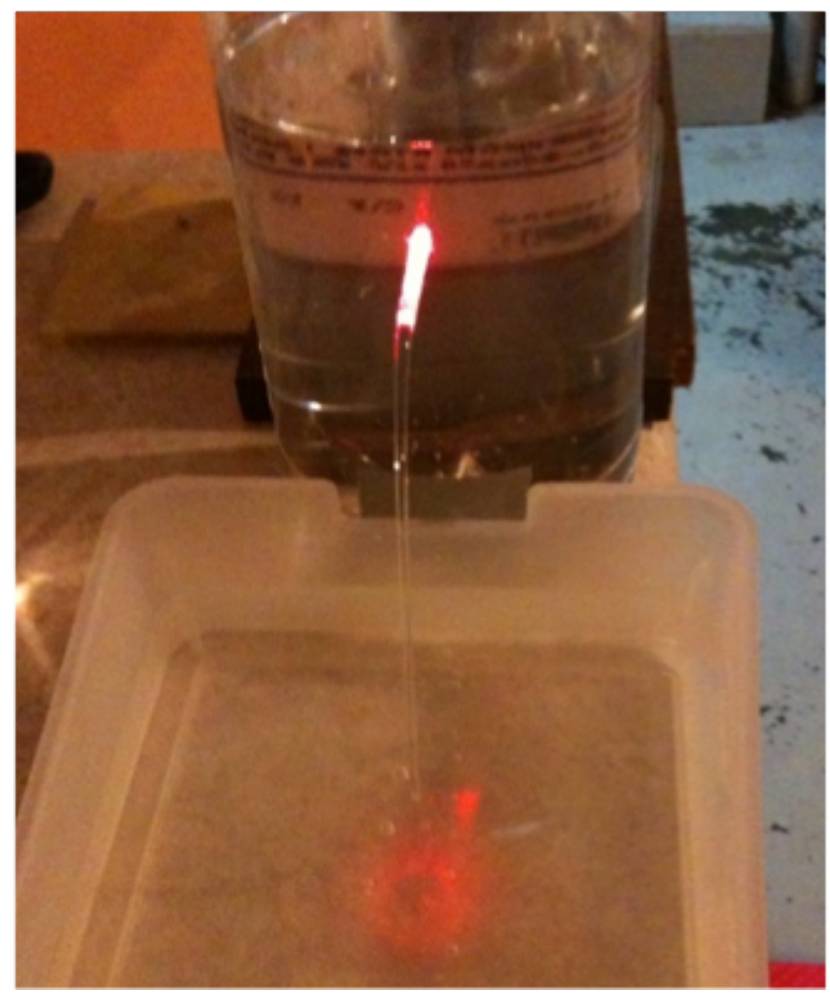

Figure 1. Total internal reflection of laser light within a curved stream of water. Note the ring of red light in the catch tray.

At this point, the students have performed three separate handson experiments to see how the path of light can be changed, two of which show how total internal reflection allows the light to stay within a material. Students can now easily understand how light can travel via fiber optic cables used for communications. To demonstrate this we ask them to shine light into the end of a very long, looped, fiber optic cable and see that light appear on the other end. The students are able to apply their newly acquired knowledge to explain to us how this occurs.

In our observation, there are several factors that make this a successful exercise, namely: limited lecture; an abundance of hands-on work; time to tinker; and real-world application.
This experiment is easily repeated at home and adapted for classroom use by teachers in a K-12 setting. Instructions on how to construct the required materials will be online [10] prior to completion of the final version of this paper and well in advance of the XSEDE12 conference.

The earliest version of this demonstration was developed by Steven Wallace with help from Camillo Viecco (both of Indiana University), for inclusion in a booth display at the IEEE/ACM $\mathrm{SC}$ conference. It can be done so quickly that it is suitable for public information purposes in any sort of booth display. PTI has used this display in a booth at a very large public Indiana educational event Celebrate Science Indiana [3]. Thousands of people attend this state-centric event that "aims to highlight the importance and value of science, technology, engineering, and mathematics (STEM) education, research, and careers to Indiana and all Hoosiers." Several hundred attendees saw this demonstration 2011 Celebrate Science Indiana event. This particular demonstration is useful in Indiana - and potentially useful in other states - due to the ease with which it allows our staff to explain the value of public research networks. The ILight network connects all higher education institutions in the state of Indiana (public and private) to each other and to national research and education networks. This network was built with two separate allocations of state funds. Using this demonstration in a booth at lay public outreach events provides an opportunity to explain what the I-Light network is and why a publicly funded statewide research and education network aids the state.

\subsubsection{Lego Mindstorms ${ }^{\circledR}$ Robotics Programming Workshops}

The learning goal of our implementation of the Lego Mindstorms $^{\circledR}$ Robotics Programming Workshops is to teach critical thinking and the core elements of structured programming. Specifically, the students are given a goal: program your robot to navigate a particular course or set of turns and movements. This requires learning structured thinking (as well as the particular programming commands) to complete that task. Students work in small groups (up to four students working together). The students learn to understand their overall challenge well enough to break it into smaller, solvable problems. They also learn to apply freshly acquired skills, make modifications based on test results, and learn to work within a group.

We have delivered such workshops - locally branded as "RobotCamp" - to a variety of age groups (grades 4-6, 6-8, 812 , etc.). Our focus has been on programming the robots - i.e., providing pre-constructed robots to the students, rather than spending time building them. The programming challenges are then tailored to the specific age group and time constraints for a particular workshop.

Materials needed in addition to the Lego Mindstorms ${ }^{\circledR}$ kit depend upon the task at hand. As an example, one programming challenge we have used repeatedly with 8-12 graders requires the students to create a program to use an infrared (IR) sensor to discover an IR-emitting ball, navigate the robot towards the ball and grasp it, all autonomously. This requires an IR source (IRemitting ball or IR source and separate ball) and an arena to contain the robot and ball. It is also important to have a large pad of paper or whiteboard available for planning out algorithms and discussing ideas.

In any of the robot workshops, after an initial introduction to the programming environment and the capabilities of the robot, the 
primary role of the teachers becomes making suggestions to guide teams of students toward accomplishing their goal. The students feel the greatest sense of satisfaction from learning from their own mistakes and then getting the job done right on their own. One of the most useful things the group leader can do is drag the students away from the programming software and guide them through a verbal discourse of what they are trying to accomplish using pen and paper. Once the students agree on some of the details of a method or two for how to proceed, it becomes much easier to return to the programming environment and develop the program. It is important to prevent relatively random clicking and dragging that isn't coupled with real thought about what needs to be accomplished.

The workshops end with a friendly competition in the course of which the students explain their particular programming algorithm for reaching the goal. This is useful to the explaining team, because it requires them to know their algorithm well enough to explain it to others, and the other groups learn of a technique that is very likely different from their own. Students particularly enjoy final tuning of their programming and algorithms, cheering their own robots on, and watching the other students' robots. This makes for an upbeat ending to the workshop, but also serves as a marker of success. The students care enough to work on their robots to the very end, and they have learned enough to observe the robot, know what changes they want to make, and execute those changes on their own.

\subsubsection{No guts, no glory}

The learning objectives of the "No guts, no glory" workshop are teaching the basics of networking concepts, computer systems components and operating systems, and parallel computing. These sessions are part of the Minority Engineering Advancement program given every summer by the Purdue School of Engineering at the Indiana University - Purdue University Indianapolis campus. This event consists of three separate but related half-day events. Students are typically in high school, but a few junior high school students are involved each year.

The first of the three workshops is devoted to network concepts. This session begins with a discussion of network layers and IP routing and ends with a hands-on exercise where the students role-play parts of the network to transfer data. The aim of this workshop is to build students' comfort and familiarity with networking concepts. Students take the part of various network components in a "human network" of people in a room where network paths are taped out on the floor. For example, one exercise has the following steps:

- The person whose identity in the human network is "Student@Computer" explains aloud their first request. The usual first request is "image of a Space Shuttle," so the student writes that on a piece of paper and places the request in an envelope.

- Next, this student writes on the envelope a "To:" and "From:" IP address. "To:" might be the IP address of Google, and "From:" will be the computer's own IP address.

- Next, the person who is "Student@Computer" passes the envelope to the student who is acting as "Local Router."

- The Local Router will look at the "To:" IP address and decide where to send the envelope next (probably another router); their choice should be the least number of hops away.
- This action is repeated until the envelope reaches the Server.

- The Server will open the envelope and read the request aloud.

- The Server will sift through available content (a pile of printouts located at the place where the server stands in the room) to find the appropriate picture.

- The Server places the content in a new envelope.

- The Server will address the envelope with "To:" as the IP address of the requesting computer, and "From:" as the address of itself.

- Now the Server passes the envelope back to its nearest router, and the routers perform a similar task as before, but the To: and From: are different this time.

In the end, Student@Computer should receive the correct content. This seems a bit hokey, but the students clearly enjoy the exercise - particularly trying to intuit the paths with the fewest hops. Figure 2 below shows students doing this exercise. Staff who have taught this class all believe that this exercise is more fun than any lecture they have heard on the OSI 7-layer network model.

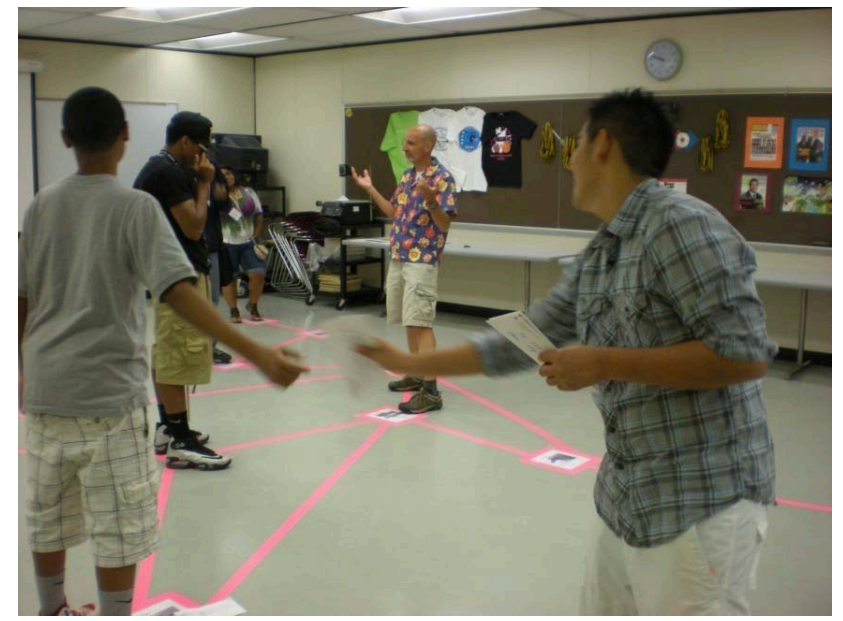

Figure 2. Students manually passing data packets in a networking and routing workshop.

The second day of this workshop is a similar version of the Lego Mindstorms ${ }^{\circledR}$ Robotics Programming Workshop described earlier, however because this is an engineering program, some modification of the robot itself is also permitted.

The third day of this workshop is about computer components, operating systems, and supercomputers. It is this session that gives the overall event its "No guts, no glory" title. This kicks off with a talk about computer components (guts) followed by an activity where the students build a computer from components (RAM, hard drive, video card, CD-ROM drive, IDE cables, power cables, NIC, etc.). Once the computer is built they use BCCD to see if the machine can boot and load an operating system and so an ad hoc cluster is produced, if time permits example parallel jobs can be run on the cluster. The next segment starts with an overview of parallel computers (supercomputers). This includes discussion of what they are, how they work, and examples of research that is performed using them, followed by a hands-on exercise that lets the class form a "human supercomputer" much like the first day has the class form a "human network." The task presented to the class is to solve a $500+$ piece jigsaw puzzle. The puzzle would normally 
take 5-6 hours to complete, and the students work together to solve it in about 30 minutes. This is accomplished by distributing the puzzle pieces to small groups of students, who use the information on the back of each puzzle piece to sort and solve small sections of the puzzle. Some of the same issues that are encountered during real parallel programming efforts (contention, load balancing) arise during the students' puzzle solving, and a discussion about this follows the completion of the puzzle. Lastly, a session is presented on cloud computing and storage, as well as virtual machines.

\subsection{Teaching the Teachers}

Our engagement in teaching the teachers has included workshops at $\mathrm{SC}$ as well as distribution of materials that can be used in educational and outreach events.

\subsubsection{Workshops at SC10}

The most tangible outreach we have performed for teachers thus far was a workshop at the Supercomputing Conference in 2010 (SC10) [7]. This presentation was part of the SC10 Education Program's larger Teacher Day. We provided a presentation to teachers from the Louisiana area about the history of our EOT involvement, the types of workshops we provide, the number of participants, our partners, fairly detailed instructions on how to conduct the workshops, and typical student responses.

We covered the following workshops: No Guts, No Glory (assembling computers from components and then clustering them with Bootable Cluster CD [2]); Virtualization, Cloud Computing and Cloud Storage; Be a SuperComputer (solving a jigsaw puzzle quickly, by hand, by working in parallel); Networking and Routing (role-playing networking components and manually performing data transfer, see Figure 2); and Lego Mindstorms ${ }^{\circledast}$ Programming. Our hope was that our presentation, combined with printed and electronically available handouts [10], would allow the teachers to perform the workshops in their own classrooms with limited preparation and research.

\subsubsection{Stereoscopic 3D Science Films}

Two computer-generated, three-dimensional films have been made available to K-12 instructors: "A Universe of Questions," on astronomy; and "LEADing the Way," on weather and climate. Indiana University's Advanced Visualization Lab created the films in conjunction with the TeraGrid EOT efforts sponsored by the National Science Foundation ${ }^{1}$. Several of the authors of this paper and volunteers from TeraGrid and partnering institutions participated in a variety of events, presenting these films to K-12 instructors and often to their students as well.

Instructors were very interested in the films, which were distributed at no charge for classroom use. We witnessed numerous "aha" moments in the exhibition booths as the students gained basic insights into the fields of astronomy and weather prediction We encouraged the instructors to use the National Science Digital Library [13] to include the 3D films in their curricula. These movies are available (and will remain available) online [6], licensed to enable distribution and reuse.

\footnotetext{
${ }^{1}$ NSF Grant number OCI-0503697
}

\subsubsection{Distributing Materials To Local and National Communities \\ The materials needed to put on the educational and outreach events described earlier are available online [10] and licensed so that they may be reused and modified. \\ 4. EVALUATIONS AND SUCCESSFUL TECHNIQUES}

We begin this section by noting that none of the group leaders are trained in education, though many have teaching experience. The basic process by which these events are put on and made successful is that the staff involved are dedicated to education and enjoy the opportunity to positively influence young people. Every group of young people is unique, and we begin each event with a short, informal introduction. This breaks the ice and allows the instructor some quick insight into the level of knowledge and experience of the students and what they find most interesting. We are very careful to minimize lecture time and maximize group activity time.

In terms of structuring group activities we have found that the best approach is to assign one staff member to serve as a mentor to a group of students and have that staff member work with the same group throughout the entire event. This allows for developing a strong rapport with students, understanding that specific group's dynamics, and understanding how they are approaching the task. In our experience, this arrangement allows the students to have someone specific to report their progress to and share their frustrations and triumphs with as they solve each part of a problem.

The staff members serving as group mentors often interject anecdotal stories or comments relating a task at hand to something they get to do as part of their job. This is a good way to convey to students that the things they are learning can be applied in real jobs that real people have - and therefore could be part of the student's career in the future. It is absolutely essential to have enough staff on hand to have effective and enjoyable workshops. A minimum is one staff member per four participants, plus one room leader, plus one person to troubleshoot problems, run errands, etc.

Environment is an important factor. Group work is effective only in a room set up to support group work - which means not a room set up with desks in rows.

Time for tinkering is important. Some very creative student ideas have come out of what was initially just playing around. While each workshop has a specific learning goal in mind, there should be enough flexibility to try something tangential and see what happens.

\subsection{Measures of Success}

It is difficult to quantify the success of an outreach activity. It is much easier to tell qualitatively whether you reached the students. The sort of markers of success we take note of are: student engagement; asking thoughtful questions; successful contributions from all group members; excitement and pride in achievements; students feeling that they accomplished something by the end; and excitement in sharing the details of the day with parents and other adults.

Each EOT event generates information for formative evaluations that permit us to improve the workshop over time. The feedback we get from students - verbal and body language during the event, comments at the end of an event - let us know which parts of a workshop are well received and which parts need to be 
improved upon. Other evaluation data are in the form of events that reach their full enrollment capacity faster every year and partners such as the Minority Engineering Advancement Program that invite us back year after year and ask us to do longer and more detailed programs each time. Table 2 shows annual participation numbers for two outreach events.

The best and primary summative evaluations in all of the workshops we do are found in the Robot workshops: did the student groups succeed in programming their robots to complete the assigned challenge? Our success rates have hovered consistently near $100 \%$ - only once in the history of our Robot Camp offerings did a student group fail to successfully program their robot to complete the assigned task. The other very clear summative evaluation is in the "No guts, no glory" workshop in the form of full success of student groups to build a computer that will boot up and run.

Table 1: Summary of EOT Events

\begin{tabular}{llll}
\hline Event & $\begin{array}{l}\text { Grade of } \\
\text { Participants }\end{array}$ & $\begin{array}{l}\text { Number of } \\
\text { Participants } \\
\text { Annually }\end{array}$ & $\begin{array}{l}\text { Years of } \\
\text { Participation }\end{array}$ \\
\hline $\begin{array}{l}\text { PTI Robot } \\
\text { Workshop }\end{array}$ & $8-12$ & 48 & $2007-2011$ \\
\hline $\begin{array}{l}\text { Minority } \\
\text { Engineering }\end{array}$ & $6-11$ & $85-90$ & $2007-2011$ \\
$\begin{array}{l}\text { Advancement } \\
\text { Program } \\
\text { (MEAP) }\end{array}$ & & & \\
\hline $\begin{array}{l}\text { Informatics } \\
\text { Summer }\end{array}$ & & & \\
Camp & & 25 & \\
\hline $\begin{array}{l}\text { ExxonMobil } \\
\text { Bernard }\end{array}$ & $6-8$ & 54 & \\
$\begin{array}{l}\text { Harris } \\
\text { Science Camp }\end{array}$ & & & \\
\hline WonderLab & $4-6$ & & \\
Science Camp & & $2009-2011$ \\
\hline $\begin{array}{l}\text { Celebrate } \\
\text { Science }\end{array}$ & All Ages & Hundreds & 2011 \\
Indiana & & & \\
\hline $\begin{array}{l}\text { SC 10 } \\
\text { Teacher Day: } \\
\text { No Guts, No }\end{array}$ & & & \\
Glory: Dare to & & & \\
Excite Your \\
$\begin{array}{l}\text { Students With } \\
\text { Technology }\end{array}$ & & & \\
\hline $\begin{array}{l}\text { TOTAL NUMBER OF } \\
\text { PARTICIPANTS }\end{array}$ & & \\
\hline
\end{tabular}

It will be decades before we can know what careers the young people who attend these EOT workshops will pursue, and how successful they will be in those careers. This measure of success cannot be incorporated into the yearly cycle of developing workshops. However, we have formed a collaboration with the IU School of Education to add surveys and seek funding for some longitudinal studies on the impact of workshops on student interests and careers. We are also planning to develop formal relationships and collaborations with local school districts, so that the interest generated in workshops carries over into educational activities performed in a formal education setting. We are also working to publicize the availability of the curriculum resources we have prepared, so that the workshops described here can be used in schools in Indiana.

The number of people participating in outreach and educational events is the most basic metric of success - are people attending? Table 1 provides data for outreach workshop events that used at least one of the activities described in this paper.

Having started our outreach and educational workshop events in 2007 with very little funding from within IU, and no external funding, we feel confident in asserting the following as an overall evaluation: What we had in terms of formal funding for outreach and educational workshops was almost nothing. What we have accomplished is quite something - we have encouraged interest in technology for hundreds of students, for at least a short time. We have enabled them to learn something about technology and critical thinking, and to demonstrate to themselves that they are capable of such learning.

\section{THE COST OF OUTREACH}

The largest cost for us is staff time. For most of the staff involved the staff time is a small amount of time in a preparatory session, plus the actual workshop itself. For a few staff it will be a sizeable amount of time spent preparing the workshop content and materials, plus performing dry runs to make sure that the workshop will flow smoothly. In addition to the technical staff that lead the workshops, there is also an administrative cost of advertising the workshop; providing a mechanism for sign-up; managing the arrival and departure of the students, reserving rooms, and other logistics. Examples of the number of staff hours needed to prepare and complete a workshop are in Table 3.

The next largest cost is that of the materials which is most significant in the case of Lego Mindstorms ${ }^{\circledR}$, but this is a onetime cost (we are still using all the kits purchased six years ago). For daylong workshops we may also provide a lunch and refreshments for the students. In recent years, we have sought sponsorship from university business partners and local merchants, and now have secured external support for the full cost of the Robot Camps in 2012. The cost of materials varies with the type of workshop, but most equipment costs are onetime costs as the material can be reused. Additionally, we need a physical space to do preparation and staff training as well as the actual workshop.

\section{Risk Management}

Providing a safe environment for children is an essential aspect of all K-12 programs. This includes both physical safety of the children and their emotional well-being. By the same token, it is important to protect the teaching institution and its staff from liabilities and negative publicity in case of unfounded allegations of abuse.

As a commitment to providing a safe environment, Indiana University has developed a policy for programs involving children [8], therefore we do not need to develop separate policies for our EOT programs. The goal of the policy is to safeguard the children, mitigate the risk to the university, and ensure that staff comply with state and federal laws regarding reporting abuse. Group leaders working with children must be familiar with the policy, attend a Risk Management training session on child protection and prevention of sexual abuse, and must undergo an annual background check. Measures we have implemented include the following: Program organizers work with children's parents regarding any special 
Table 2: Attendance Figures For Robot Camp and No Guts, No Glory

\begin{tabular}{llllllll}
\hline Activity & $\mathbf{2 0 0 7}$ & $\mathbf{2 0 0 8}$ & $\mathbf{2 0 0 9}$ & $\mathbf{2 0 1 0}$ & $\mathbf{2 0 1 1}$ & $\mathbf{2 0 1 2}$ (est.) & Total \\
\hline Robot Camp & 15 & 15 & 15 & 96 & 102 & 112 & 355 \\
\hline No Guts, No Glory & 45 & 24 & 31 & 28 & 31 & 30 & 190 \\
\hline
\end{tabular}

Table 3: Examples of Staff Hour Costs for EOT Events in 2011

\begin{tabular}{llllll}
\hline Event & $\begin{array}{l}\text { Number of } \\
\text { Participants }\end{array}$ & Grade Level & Preparation Time & Presentation Time & Event Duration \\
\hline Lego Mindstorms & 102 & $7-8^{\text {th }}$ & 76 & 372 & 38 \\
\hline No Guts, No Glory & 31 & $6-7$ th & 70 & 48 & 7 \\
\hline
\end{tabular}

needs, such as medications or food allergies, and qualified staff are available to handle medical emergencies. Children are under the supervision of more than one adult at all times and telephone contact is available to the parents in case of any unforeseen events. Generally, when dealing with children, we do not rely on any single point of failure, and in all cases err on the side of caution. The university also recognizes that some flexibility is required depending upon the nature of the workshop.

\section{PLANS FOR THE FUTURE}

While we continue to fine tune and in some cases re-invent the content of programs we have offered for many years, we have a deliverable on hand that we would like to share with a larger audience. There are a few ways we are considering approaching this challenge. One is to pursue a partnership with the IU School of Education and offer a summer workshop for teachers who are participating in continuing education. The course would include details on the mechanics and best practices for leading the EOT workshops that we have experience delivering. A similar workshop could be offered to local teachers as well. The work we did for the SC10 Teacher Day would be the starting point for developing such a course. The goal of training teachers to lead these workshops is to expose a larger number of students to IT, science, and advanced technology.

In the case of the fiber optics workshop, we have considered creating YouTube videos to describe to a teacher what materials are needed, the science behind the hands-on experiments, and how to lead the students through the entire exercise. This could then be available as a resource for any teacher to use in their own classroom, thereby reaching a greater audience and allowing teachers to incorporate this into their lessons as appropriate.

A formal Lego League [4] already exists and is led by IU staff. We now encourage attendees of our Lego Mindstorms ${ }^{\circledR}$ workshops to join the Lego League. This group works yearround to develop skills for an annual competition. The Lego League members could also be leveraged to serve as group leaders in some of the Lego workshops we lead. This is beneficial for the League members because they gain depth of knowledge, it allows us to slightly reduce the number of fulltime staff hours spent at the camp, and it allows for peer-to-peer learning which would be a nice complement to the adult technical staff group leaders.

Following up on the existing 3D science films, we plan to create additional films around other scientific topics, with the next film based on biological sciences. These materials will be licensed for re-use. Given the accessibility of 3D television screens, we believe that 3D technology will become increasingly accessible and adopted within public school and residential homes.
In keeping with the goals of the information technology strategic plan the IU School of Education has agreed to take on a leadership role for K-12 technology outreach for IU as a whole. Additionally, the Pervasive Technology Institute will work with the School of Education to improve upon current EOT programs, create new programs, and develop specific lesson plans incorporating our EOT exercises into a K-12 curriculum.

\section{Conclusions}

XSEDE has made a difficult but reasoned decision not to invest directly in K-12 outreach. This decision does not take away from the tremendous need to encourage young people to be interested in technology. Interest is just one early component of what is needed for successfully nurturing and educating a person who eventually pursues a career in a STEM field - but interest is a critical starting point. Interest drives student choices in taking classes in junior high and high school, and everything else follows from the selection of those classes. In this paper we describe three different workshop events that can be put on with just the cost of staff time and very modest material expenses.

\section{REFERENCES}

[1] ACT. Developing the STEM Education Pipeline. 2006. Available from: http://www.act.org/research/policymakers/pdf/ACT_STEM _PolicyRpt.pdf [cited 24 May 2012]

[2] Bootable Cluster CD (BCCD). Home page. Available from: http://bccd.net [cited 18 Apr 2012]

[3] Celebrate Science Indiana. Home page. Available from: http://www.celebratescienceindiana.org/ [cited $18 \mathrm{Apr}$ 2012]

[4] FIRST. FIRST LEGO League. Available from: http://www.usfirst.org/roboticsprograms/fll [cited 24 May 2012]

[5] Indiana University. Empowering People: Indiana University's Strategic Plan for Information Technology. 2009. Available from: http://ep.iu.edu/ [cited 6 Jan 2011]

[6] Indiana University. Generating Interest in Science and Technology using Stereoscopic 3D Videos. Available from: http://3d.iu.edu/ [cited 3 Apr 2012]

[7] Indiana University. Teacher Day: No Guts, No Glory: Dare to Excite Your Students With Technology. Available from: http://sc10.supercomputing.org/schedule/event_detail.php? evid=comm133 [cited 18 Apr 2012]

[8] Indiana University. University Policies: Programs Involving Children (PS-01). Available from: http://policies.iu.edu/policies/categories/administration- 
operations/public-safety-institutional-assurance/PS01.shtml [cited 24 May 2012]

[9] Indiana University Pervasive Technology Institute. Home page. Available from: http://www.pti.iu.edu/ [cited $12 \mathrm{Sept}$ 2011]

[10] Indiana University Pervasive Technology Institute. Outreach Resources. Available from: http://pti.iu.edu/eot/resources [cited 18 Apr 2012]

[11] McRobbie, M.A. Inaugural address of Michael A. McRobbie: Endurance, Excellence, and the Energy of Change at Indiana University. Available from: http://www.iu.edu/ pres/speeches/2007/20071018-01.shtml [cited 18 Apr 2012]
[12] Miller, T., B. Plale and C.A. Stewart. Annual report on training, education, and outreach activities of the Indiana University Pervasive Technology Institute and affiliated organizations. 2012. Available from: http://hdl.handle.net/2022/14132 [cited 23 Jan 2012]

[13] National Science Digital Library. Home page. Available from: http://nsdl.org [cited 25 Apr 2012]

[14] President's Council of Advisors on Science and Technology. Engage To Excel: Producing One Million Additional College Graduates With Degrees in Science, Technology, Engineering, and Mathematics. 2012. Available from: http://www.whitehouse.gov/sites/default/files/microsites/os tp/fact_sheet_final.pdf [cited 24 May 2012] 